\title{
Influence of Straw Fiber on the Insulation Properties and Frost Resistance of the Cement Based Materials
}

\author{
Jing-hui $\mathrm{LI}^{1, \mathrm{a}^{*}}$ and Li-guang XIAO ${ }^{2, \mathrm{~b}}$ \\ ${ }^{1,2}$ School of Materials Science and Engineering, Jilin Jianzhu University, Changchun \\ 130118,China \\ ajh_1231@163.com, bxlg627@163.com
}

\begin{abstract}
The composite material is composed of low alkaline magnesium oxychloride cement as base material and plant straw fiber as reinforcement material. Further, the thermal conductivity was measured to characterize the thermal insulation properties of composite materials. The influence of straw fiber on the frost resistance of composite materials was investigated after 50 freeze-thaw cycles.
\end{abstract}

\section{Introduction}

With the development of agriculture in China, the number of straw rose sharply, reaching about 7 million tons each year. Quite a large portion of the straw had been "burned up", wasting a lot of biological resources, also producing haze seriously and damaging the ecological environment. The utilization of crop straw had became a social problem which had great significance. On the other hand, the cement based material was the largest engineering materials in the world. It was characterized of high compressive strength, but also showing some disadvantages such as low flexural strength, toughness, and easy to crack. Using fibers in cement might be an important way to solve above problems[1-4]. This work mainly studies on the effect of straw fiber on the heat preservation and frost resistance of cement-based material.

\section{Experimental Procedures}

\subsection{Main raw materials and properties}

Magnesium oxide: active magnesium oxide used in the preparation of magnesium oxychloride cement, its main source is the magnesite stone $\left(\mathrm{MgCO}_{3}\right)$ through $750-850^{\circ} \mathrm{C}$ high temperature calcination and grind, it is a pale yellow powder. Its physical properties are as follows: the density of $3.2 \mathrm{~g} / \mathrm{cm}^{3}$, the fineness of $120 \mathrm{mesh} / \mathrm{cm}^{2}$, sieves margin $\leq 1.5 \%$. Chemical composition is as follows: $\mathrm{MgO}$ is $81.4 \%, \mathrm{CaO}$ is $1.2 \%$ and the burned loss is $8 \%$;

Corresponding author:ljh_1231@163.com 
The halogen powder: halogen block should be soluble in water, the insoluble precipitation is less than $0.5 \% ; \mathrm{MgCl}_{2}$ content is more than $45 \% ; \mathrm{SO}_{4}{ }^{2-}$ content is less than $2 \%$; $\mathrm{NaCl}$ content is less than 2\%; Straw fiber: corn stalk was broken into $1 \mathrm{~mm} \sim 15 \mathrm{~mm}$ of fibrous; Straw surface modification agent: using modified EVA-PVFM copolymer latex made by self; Phosphoric acid: chemical constituents: $\mathrm{H}_{3} \mathrm{PO}_{4} \geq 85 \%$; Residue on ignition $0.2 \%$; Chloride $0.0003 \%$; Sulfate 0.003\%; Nitrate 0.0005\%; Mn 0.0002\%; FeO 0.002\%; Heavy metal $0.001 \%$; Silicone (JHG-621 sodium silicate): appearance, light yellow liquid; Specific gravity: 1.20-1.26; Sodium methyl silicate is $20 \%$; Sand: using middle sand with graded gradation, the fineness modulus of 2.8; Water reducer: using UNF high efficiency water reducing agent; Fly ash: fly ash of the Changchun FAW Group power plant. it is used after fine grinding, its chemical composition shown in table 1.

Tab.1 Chemical Compositions Of Fly Ash (Mass \%)

\begin{tabular}{|c|c|c|c|c|c|}
\hline Loss & $\mathrm{SiO}_{2}$ & $\mathrm{Al}_{2} \mathrm{O}_{3}+\mathrm{TiO}_{2}$ & $\mathrm{Fe}_{2} \mathrm{O}_{3}$ & $\mathrm{CaO}$ & $\mathrm{MgO}$ \\
\hline 7.78 & 59.93 & 20.16 & 4.24 & 0.92 & 1.45 \\
\hline
\end{tabular}

\subsection{Main experimental equipment}

WDW-20, precision is $0.2 \mathrm{KN}$; Instrument of thermal conductivity: DRY-300; The test machine of freeze-thaw: -40FDs-500; Scanning electron microscope: KYKY-2800B, beijingzhongke keer intrument company.

\subsection{Experimental method}

Thermal insulation properties of materials were characterized by measuring thermal conductivity. The thermal conductivity of the material was directly measured by a meter of thermal conductivity. Thermal conductivity was defined on the conditions of stable heat transfer. Thickness of material was $1 \mathrm{~m}$ and temperature difference of the surface of both sides was 1 degree ( $\mathrm{K}$ ), heat was transferred through $1 \mathrm{~m}^{2}$ area in 1 hour. Test block with a size of $300 \mathrm{~mm} * 300 \mathrm{~mm} * 30 \mathrm{~mm}$, was cured for about 28 days and then dried for 3 days in drying box $\left(\mathrm{T}=110^{\circ} \mathrm{C}\right)$. The thermal conductivity of the material was measured by a meter of thermal conductivity and accurate to 0.001 .

Composite materials would been damaged in alternative physical effects in natural conditions, specifically, wet and dry, cold and hot, freezing and thawing, etc. Frost resistance can be regarded as an important indicator of the long-term durability of composite material. In this stuy, 50 freeze-thaw cycles at the range of $-25^{\circ} \mathrm{C}$ to $20^{\circ} \mathrm{C}$ were performed to test antifreeze durability of the composite materials. The loss rate of strength was less than $25 \%$, the mass loss rate was less than $5 \%$, i.e. the frost resistance of composite is qualified. We could see from table2.

Tab.2 The Formulation Of Composite Materials Used For Freeze-Thaw Experiments

\begin{tabular}{|c|c|c|c|c|c|c|c|c|}
\hline +Directio & $\mathrm{MgO}$ & $\begin{array}{c}\text { The } \\
\text { solution } \\
\mathrm{n}\end{array}$ & $\begin{array}{c}\text { Sand } \\
(\mathrm{g})\end{array}$ & $\begin{array}{c}\text { Fly } \\
\text { ash } \\
(\mathrm{ml})\end{array}$ & $\begin{array}{c}\text { Phosph } \\
\text { ate }(\mathrm{ml})\end{array}$ & $\begin{array}{c}\mathrm{UN} \\
\mathrm{F} \\
(\mathrm{g})\end{array}$ & $\begin{array}{c}\text { Untreated } \\
\text { straw fiber } \\
(\mathrm{g})\end{array}$ & $\begin{array}{c}\text { Treated } \\
\text { straw } \\
\text { fiber }(\mathrm{g})\end{array}$ \\
\hline $\mathrm{A}$ & 100 & 90 & 250 & 0 & 0 & 0 & 0 & 0 \\
\hline $\mathrm{B}$ & 100 & 90 & 250 & 10 & 1 & 0.75 & 0 & 0 \\
\hline $\mathrm{C}$ & 100 & 90 & 250 & 10 & 1 & 0.75 & 5 & 0 \\
\hline $\mathrm{D}$ & 100 & 90 & 250 & 10 & 1 & 0.75 & 0 & 5 \\
\hline
\end{tabular}




\section{Experimental Results and Discussion}

\subsection{Influence of straw fiber on the thermal insulation properties of the cement based materials}

The tested results of thermal conductivity were shown in table 3 and figure 1. From table 3 , we could see that the thermal conductivity of the composite material was reduced with increasing the amount of straw. Thermal insulation properties of the composite material were imporved with increasing the amount of straw. Further, we could see the porous microstructure of straw. When it was packaged by the hydration products of magnesium cement, these pores were sealed, resulting in the increased thermal insultion of composite.

Tab.3 The Influence Of Straw Content On The Insulation Properties Of Composite

\begin{tabular}{|c|c|}
\hline The content of strawt $(\%)$ & Thermal conductivity $(\mathrm{W} / \mathrm{m} \cdot \mathrm{k})$ \\
\hline 0 & 0.296 \\
\hline 2 & 0.247 \\
\hline 3 & 0.210 \\
\hline 7 & 0.181 \\
\hline 12 & 0.179 \\
\hline 15 & 0.152 \\
\hline 17 & 0.139 \\
\hline 20 & 0.111 \\
\hline
\end{tabular}

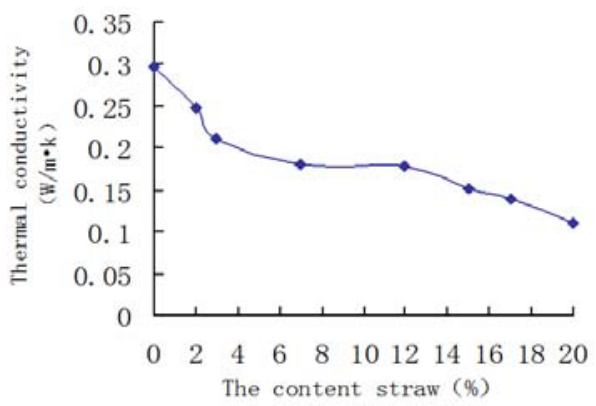

Fig.1 The relationship between straw content and thermal insulation properties of composite

Influence of straw fiber on the frost resistance of cement based materials. The influence of straw fiber on the frost resistance of cement based materials were showed in table4, figure 2 and figure 3

Tab.4 The Frost Resistance Of Composite Containing Different Contents Of Fiber

\begin{tabular}{|c|c|c|c|c|c|}
\hline Direction & $\begin{array}{c}\Delta f \mathrm{c} \\
(\%)\end{array}$ & $\begin{array}{c}\Delta \mathrm{Wn} \\
(\%)\end{array}$ & $\begin{array}{c}\text { Cycles of freeze } \\
\text { thaw }\end{array}$ & Performance of appearance & Conclusion \\
\hline $\mathrm{A}$ & 46.07 & 2.51 & 50 & $\begin{array}{c}\text { the obvious crack of } \\
\text { surface(21 times })\end{array}$ & Unqualified \\
\hline $\mathrm{B}$ & 44.94 & 2.24 & 50 & flawless & Unqualified \\
\hline $\mathrm{C}$ & 32.45 & 3.07 & 50 & flawless & Unqualified \\
\hline $\mathrm{D}$ & 12.03 & 0.63 & 50 & flawless & Qualified \\
\hline
\end{tabular}




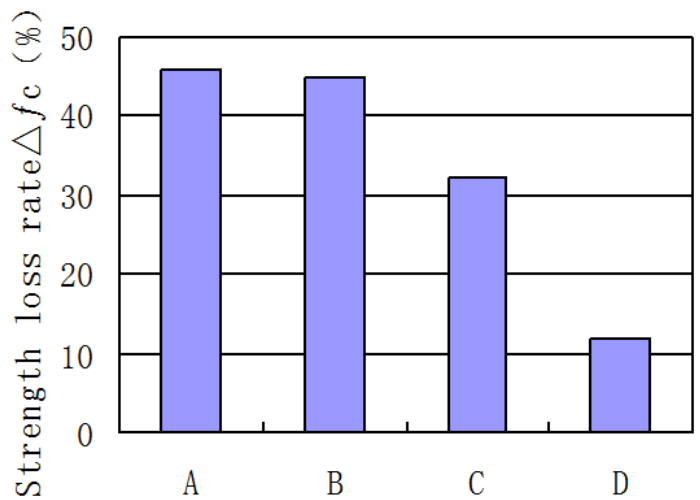

Fig.2 Strength loss rate of different directions

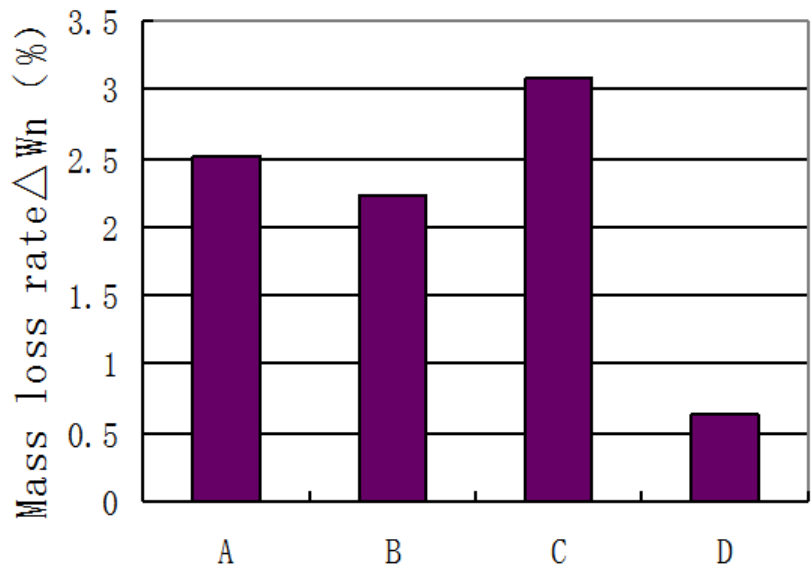

Fig.3 Mass loss rate of different directions

From table 4, we could see that strength loss rate of the reference mortar reached $46.07 \%$, which was $25 \%$ higher than Frost Resistance Standard. When fly ash, phosphoric acid and high efficiency water reducing agent were added respectively, the strength loss rate was lower as compared with the reference mortar, but the anti-freeze-thaw property was still not qualified. The strength loss rate of mortar was $30 \%$ lower than the reference mortar when non-modified straw fiber was added, but yet it has not reached the Frost Resistance Standard. The strength loss rate of mortar was $74 \%$ lower than the reference mortar when surface modified straw fiber was addied. The anti-freeze-thaw was qualified.

Mass loss rate could fully reflect the freeze-thaw resistance of the test block. The less the mass loss is, the better the freeze-thaw resistance is. The straw fiber's mass loss was very small after adding the surface modifier, it was almost no loss. Because straw fiber's surface voids were sufficiently filled with polymer, its solidity was greatly improved and water resistance of the composites was reinforced and combination with cement matrix was closer. These further improve the strength of the composite. We could see from figure 4 . Another reason was that test block was composed by inorganic materials and organic materials. After treated with polymer, the straw fiber showed improved flexibility, it could withstand freezing expansion force due to internal water freezing. 


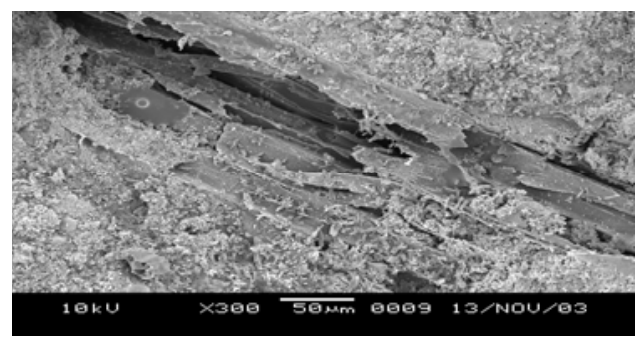

Fig.4 The microstructure of interfacial transition zone of plant fiber reinforced cement composite

\section{Conclusions}

The paper showed that the thermal conductivity of the composite material was reduced with the increase of dosed straw, i.e. The thermal insulation properties of the composite material were improved with the increase of dosed straw. Through the freeze-thaw experiments of composite materials, it can be concluded that the strength loss rate of composite mortar containing surface modified straw fiber was less than $25 \%$. Additionally, an extremely small mass loss was observed during the experiments, which indicated an improved frost resistance of composite materials.

\section{Acknowledgements}

This work was financially supported by the Jilin province comprehensive utilization of straw technology innovation platform under special foundation.

\section{References}

1. Toledo Filho R D, Gharami K, England G L et al. Development of Vegetable Fibre-Mortar Composites of Improved Durability, J. Cement \& Concrete Composites , 25(2003)585-592.

2. Mingli Cao, Cong Zhang, Microscopic reinforcement for cement based composite materials, J. Construction and Building Materials, 40(2003)14-25.

3. Jianqiang Chen, Meng Su, Judi, YeAll-Straw-Fiber Composites: Benzylated Straw as Matrix and Additional Straw Fiber Reinforced Composites[J]Polymer Composites, 35(2013)3-37.

4. Ashori, A.Effects of nanoparticles on the mechanical properties of rice straw /polypropylene composites, J. Journal of Composite Materials, 47(2013)15-36. 